\title{
Article \\ Synthesis of GaN Crystals by Nitrogen Pressure-Controlled Recrystallization Technique in Na Alloy Melt
}

\author{
$\mathrm{Xi} \mathrm{Wu}{ }^{1}$, Hongcheng Wang ${ }^{1, *}$, Dongxiong Ling ${ }^{1}$, Chuanyu Jia ${ }^{1}$, Wei Lü ${ }^{1}$, Ye Liu ${ }^{1}$, Fei Zhou ${ }^{1}$ and Zhenrong $\mathrm{Li}^{2}$ \\ 1 School of Electrical Engineering \& Intelligentization, Dongguan University of Technology, \\ Dongguan 523808, China; wuxiak@126.com (X.W.); lingdx@dgut.edu.cn (D.L.); cyjia04040@sina.com (C.J.); \\ wlv@dgut.edu.cn (W.L.); liuye@dgut.edu.cn (Y.L.); fzhou@dgut.edu.cn (F.Z.) \\ 2 Electronic Materials Research Laboratory, Key Laboratory of the Ministry of Education \& International Center \\ for Dielectric Research, School of Electronic Science and Engineering, Faculty of Electronic and Information \\ Engineering, Xi'an Jiaotong University, Xi'an 710049, China; zhrli@mail.xjtu.edu.cn \\ * Correspondence: wanghc@dgut.edu.cn
}

Citation: Wu, X.; Wang, H.; Ling, D.; Jia, C.; Lü, W.; Liu, Y.; Zhou, F.; Li, Z. Synthesis of GaN Crystals by

Nitrogen Pressure-Controlled Recrystallization Technique in Na Alloy Melt. Crystals 2021, 11, 1058 http://doi.org/10.3390/cryst11091058

Academic Editors: Andrey Prokofiev, Yuriy Zorenko, Kazimierz Fabisiak, Kazimierz Paprocki and Szymon Łoś

Received: 21 July 2021

Accepted: 28 August 2021

Published: 2 September 2021

Publisher's Note: MDPI stays neutral with regard to jurisdictional claims in published maps and institutional affiliations.

Copyright: (c) 2021 by the authors. Licensee MDPI, Basel, Switzerland. This article is an open access article distributed under the terms and conditions of the Creative Commons Attribution (CC BY) license (https:// creativecommons.org/licenses/by/ $4.0 /)$

\begin{abstract}
GaN crystals are synthesized by recrystallization technique in Na-Li-Ca alloy melt under different $\mathrm{N}_{2}$ pressure. X-ray powder diffraction results confirm that the structure of crystals is GaN with wurtzite type and there still have raw powders remaining. The total mass of GaN decreases with the nitrogen pressure reduces. No GaN crystals are found in the solution under $\mathrm{N}_{2}$ pressure of $0.4 \mathrm{MPa}$. The morphologies of the crystal are mainly prism and pyramid. The size of the crystal increases when closer to the liquid surface. Raman spectra indicates that these crystals are stress-free and crystal grown at 3.6 MPa has high structural quality or low impurity concentrations. The results reveal that the solubility and supersaturation of the solution are controlled by $\mathrm{N}_{2}$ pressure. The principle of GaN crystal synthesis by recrystallization is discussed.
\end{abstract}

Keywords: GaN; flux method; recrystallization; $\mathrm{N}_{2}$ pressure

\section{Introduction}

GaN-based materials show important applications in light-emitting diodes, laser diodes (LDs) and high-power high frequency electronic devices [1-3]. However, the lack of bulk single crystal with high quality for substrate limit their performance. In order to grow GaN crystal, several methods, such as hydride vapor-phase epitaxy (HVPE), highpressure solution growth method (HPSG), ammonothermal method and Na flux method are investigated [4-6]. Among them, the Na flux method is considered as a potential technology to obtain high quality GaN single crystal in industry because of mild conditions and high growth rate. In the late 1990s, Yamane et al. report that the GaN crystal growth conditions can be decreased to about $800{ }^{\circ} \mathrm{C}$ and $5 \mathrm{MPa}$ by $\mathrm{Na}$ flux method [7,8]. Von Dollen et al. find that the average growth rate of GaN crystal can reach $50 \mu \mathrm{m} / \mathrm{h}$, and the maximum growth rate can reach about $90 \mu \mathrm{m} / \mathrm{h}[9,10]$. Imade et al. successfully obtain dislocation free GaN crystals when the thickness reach at centimeter level by a necking technique [11]. It is found that the dislocation density in GaN crystal will be decreased with the increase of growth thickness [12,13]. Moreover, Mori et al. successfully increase the size of GaN crystal up to 6 inches by liquid phase epitaxy (LPE) technique [14]. It is reported that the dislocation density of 2-in GaN crystal can be decreased to less than $10^{3} \mathrm{~cm}^{-2}$ by combine point seed technique with LPE technique $[15,16]$.

Although Na flux method has made lots of progress, the problems of continuity and stability limit the further growth of the crystal [17]. This is because the Ga source for crystal growth in LPE technique comes from metal Ga in solution and the growth process will be terminated when it is exhausted. Moreover, the liquid level of growth solution should not be too high for inhibit the formation of polycrystals. As the result, the growth time for GaN crystal is limited to about $200 \mathrm{~h}$. In addition, the composition proportion of the 
solution always changes during crystal growth, which makes the process unstable. Aoki et al. report that $\mathrm{GaN}$ crystals can be recrystallize by cooling process and temperature gradient $[18,19]$. However, these experiments do not consider the effect of $\mathrm{N}_{2}$ pressure on crystal growth. According to the Sieverts' law, the $\mathrm{N}$ ion concentration in flux solution is closely related to nitrogen pressure, which is an important fact for GaN crystal growth [20]. In this paper, GaN crystals are synthesized by recrystallization technique in Na-Li-Ca alloy melt under different $\mathrm{N}_{2}$ pressure. The structure, morphology and quality of as grown crystals are characterized. Moreover, the effect of nitrogen pressure on crystal growth and the principle of GaN synthesis by recrystallization technique is discussed.

\section{Experimental}

As shown in Figure 1, raw materials, $\mathrm{Na}(99.5 \%), \mathrm{Li}(99.9 \%)$ and $\mathrm{Ca}(99.9 \%)$, with molar contents of $94.7 \mathrm{~mol} \%, 3.2 \mathrm{~mol} \%$ and $2.1 \mathrm{~mol} \%$, respectively, were put into the molybdenum crucible and mixed uniformly. GaN powders were placed at the bottom of the alloy melt. These powders were obtained by calcining $\mathrm{Ga}_{2} \mathrm{O}_{3}(99.99 \%)$ twice under ammonia flow at $1100{ }^{\circ} \mathrm{C}$ for $2.5 \mathrm{~h}$. The total mass of GaN powders was about $6.05 \mathrm{~g}$. The molar ratio of $\mathrm{GaN}$ powders to flux melt was about 16.4/83.6. Addition Li and $\mathrm{Ca}$ to the solution allowed the habit of the growing crystal to be easily changed to prism-shaped and increase the solubility of the solution [21,22]. This process was carried out in an Ar-filled glove box. Then the crucible was placed into a reaction tube. The gas cylinder was used to reduce the change of pressure. The temperature at the bottom of the reactor tube was heated to $855^{\circ} \mathrm{C}$ over a $4 \mathrm{~h}$ period, and the reaction tube was in a temperature gradient of about $-7.5^{\circ} \mathrm{C} / \mathrm{cm}$. The growth temperature was maintained for $100 \mathrm{~h}$. The $\mathrm{N}_{2}$ pressure kept around $0.4 \mathrm{MPa}, 3.6 \mathrm{MPa}$ and $4.5 \mathrm{MPa}$, respectively. In order to increase the fluidity of the solution, the reaction tube was rotated back and forth at the speed of $10 \mathrm{rpm}$. The furnace was naturally cooled to room temperature after growth. Finally, the crucible was taken from the reaction tube and the cold ethanol, water and hydrochloric acid were added to it to dissolve the rests of flux separately. Pure GaN crystals were obtained after ultrasonic cleaning and drying.

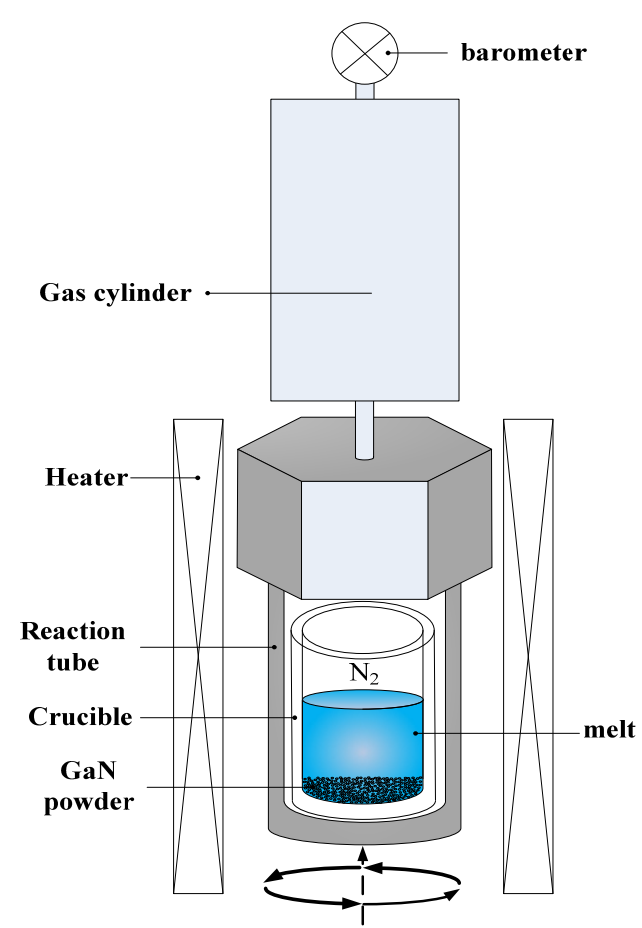

Figure 1. Schematic diagram of GaN crystal growth in Na alloy melt. 
The phase structures of the crystals before and after synthesis were analyzed by X-ray powder diffraction (XRD, Rigaku-MiniFlex600, Tokyo, Japan). The morphology of the raw GaN powders was observed by transmission electron microscope (TEM, FEI Talos F200X, Hillsboro, OR, USA). Scanning electron microscope (SEM, JSM-IT500A, Tokyo, Japan) was used to observe morphology of the crystals. The internal stress and crystal quality of the as-grown crystals were estimated by Raman system (Horiba- LabRam HR Evolution, Paris, France). The excitation source of the Raman spectrum was $532 \mathrm{~nm}$ line of He-Ne laser.

\section{Results and Discussion}

After the growth, the amount of $\mathrm{GaN}$ was weighed. The total mass of GaN crystals is $2.33 \mathrm{~g}$ and $2.50 \mathrm{~g}$ under 3.6 Mpa and 4.5 MPa, respectively. No GaN powder was found under $0.4 \mathrm{MPa}$. Figure 2 shows the X-ray diffraction pattern of the powders. The peaks of powder diffraction pattern are corresponding to the PDF\#50-0792. It indicates that the powders are GaN crystals with wurtzite crystal structure. In addition, the relative intensity of (002) diffraction peak increased after synthesis. This result may be related to the change of crystal morphology. Moreover, there are some small peaks near the diffraction peaks, which are corresponding to the GaN powders before growth. It indicates that the GaN raw materials under pressure of 3.6 MPa and 4.5 MPa did not dissolve completely after synthesis. The XRD Datas were performed by Le Bail refinement. The refined lattice constants of GaN powder are $\mathrm{a}=3.184 \AA$ and $\mathrm{c}=5.175 \AA$. The constants of GaN crystals grown at 3.6 MPa are $\mathrm{a}=3.188 \AA$ and $\mathrm{c}=5.190 \AA$. The constants of GaN crystals grown at $4.5 \mathrm{MPa}$ are $\mathrm{a}=3.190 \AA$ and $\mathrm{c}=5.188 \AA$. The results indicate that the lattice constant of the crystal will change slightly under different $\mathrm{N}_{2}$ pressure.
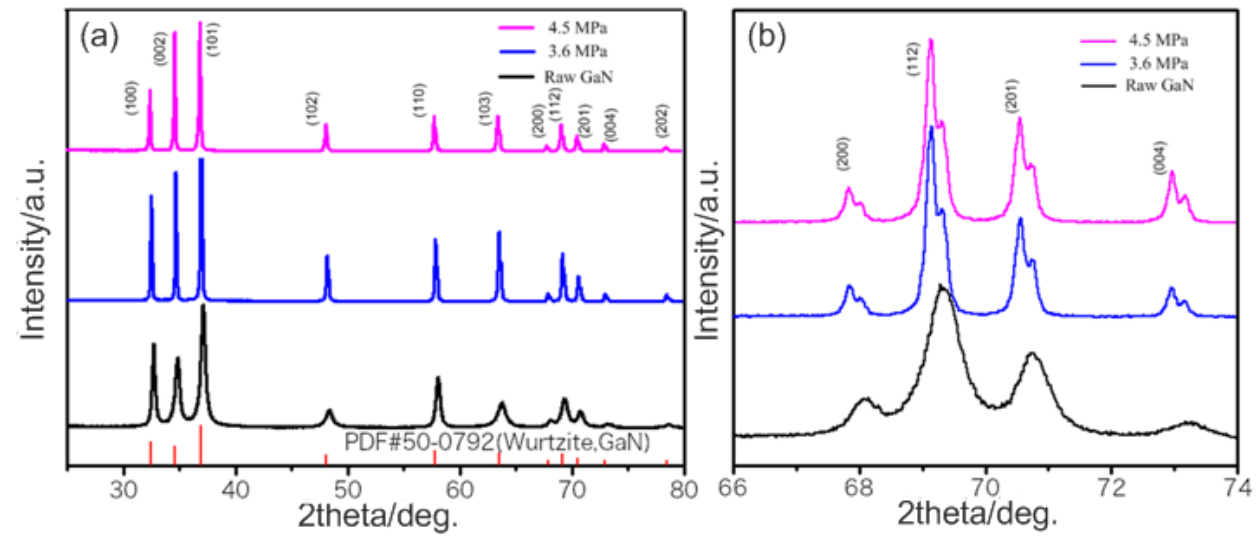

Figure 2. (a) XRD patterns of standard wurtzite $\mathrm{GaN}, \mathrm{GaN}$ powders and as grown GaN polycrystals obtained under different pressure, (b) The peak of (200), (112), (201) and (004).

Figure 3 shows the TEM images of raw GaN powders and the SEM photograph of as grown $\mathrm{GaN}$ crystal. The size of raw $\mathrm{GaN}$ powders was around $100 \mathrm{~nm}$. When the pressure was 3.6 MPa, the morphology of crystals was prism, and the crystal sizes near the liquid surface and inside the solution were $100 \mu \mathrm{m}$ and $10 \mu \mathrm{m}$, respectively. When the pressure increased to $4.5 \mathrm{MPa}$, the morphology of the crystal near the surface was prism and pyramid, and the size was about $30 \mu \mathrm{m}$. The morphology of the crystal in the solution was pyramid, and the size was about $5 \mu \mathrm{m}$. The size of GaN crystals obtained at upper solution was larger than that inside of the solution, this may be related to the difference of supersaturation. The size of the crystal is related to the supersaturation of the solution. As the supersaturation increases, the size of the crystal increases first and then decreases. Because $\mathrm{N}_{2}$ gas will dissolve into the solution, so the supersaturation of the upper solution will be higher than other place in the solution. In addition, the difference of crystal size under different pressure indicates that the supersaturation of the solution will be controlled by the nitrogen pressure. 

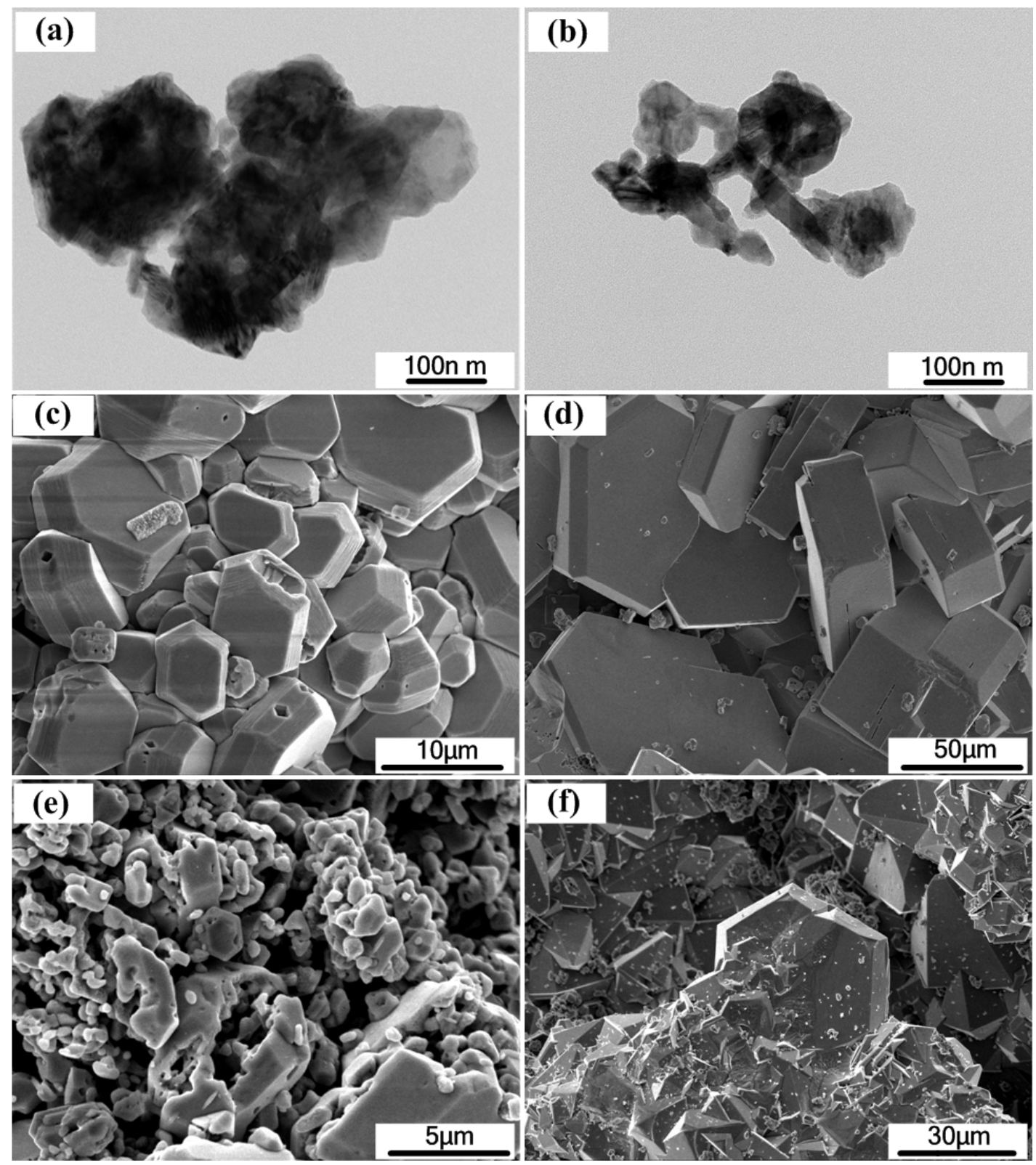

Figure 3. The TEM images of $(\mathbf{a}, \mathbf{b})$ raw GaN powders and The SEM images of typical GaN crystals obtained with N2 pressure of (c) 3.6 MPa inside the melt, (d) 3.6 MPa near the surface, (e) 4.5 MPa inside the melt, (f) 4.5 MPa near the surface.

The Raman spectra of GaN raw powder and crystals obtained under different pressures are shown in Figure 4. The peaks are observed near $567 \mathrm{~cm}^{-1}$ and $733 \mathrm{~cm}^{-1}$ in all GaN crystals, which are in good agreement with the reported $\mathrm{E}_{2}$ (high) and $\mathrm{A}_{1}(\mathrm{LO})$ phonon modes [23]. The peak position of $\mathrm{E}_{2}$ (high) is sensitive to the internal stress of $\mathrm{GaN}$ crystal. The position of $567 \mathrm{~cm}^{-1}$ corresponds to $\mathrm{GaN}$ crystal without internal stress [24]. It indicates that the crystals are nearly stress free. Moreover, the full-width at half-maximum (FWHM) values of this peak of GaN crystals grown under $3.6 \mathrm{MPa}$ and $4.5 \mathrm{MPa}$ are about $6.4 \mathrm{~cm}^{-1}$ and $18.1 \mathrm{~cm}^{-1}$, respectively. It indicates that the crystals obtained at $3.6 \mathrm{MPa}$ have higher structural quality or lower impurity concentration. The peaks of $142.4 \mathrm{~cm}^{-1}$ and $535.1 \mathrm{~cm}^{-1}$ are found in grown GaN crystals, which are corresponding to the $E_{2}$ (low) and $\mathrm{A}_{1}$ (TO) phonon modes, respectively [23]. The peak of $423.9 \mathrm{~cm}^{-1}$ is found in the GaN powder, which are corresponding to the $\mathrm{A}_{1}$ phonon mode. In addition, unknown peak was found at $271.5 \mathrm{~cm}^{-1}$, which may be related to defects. 

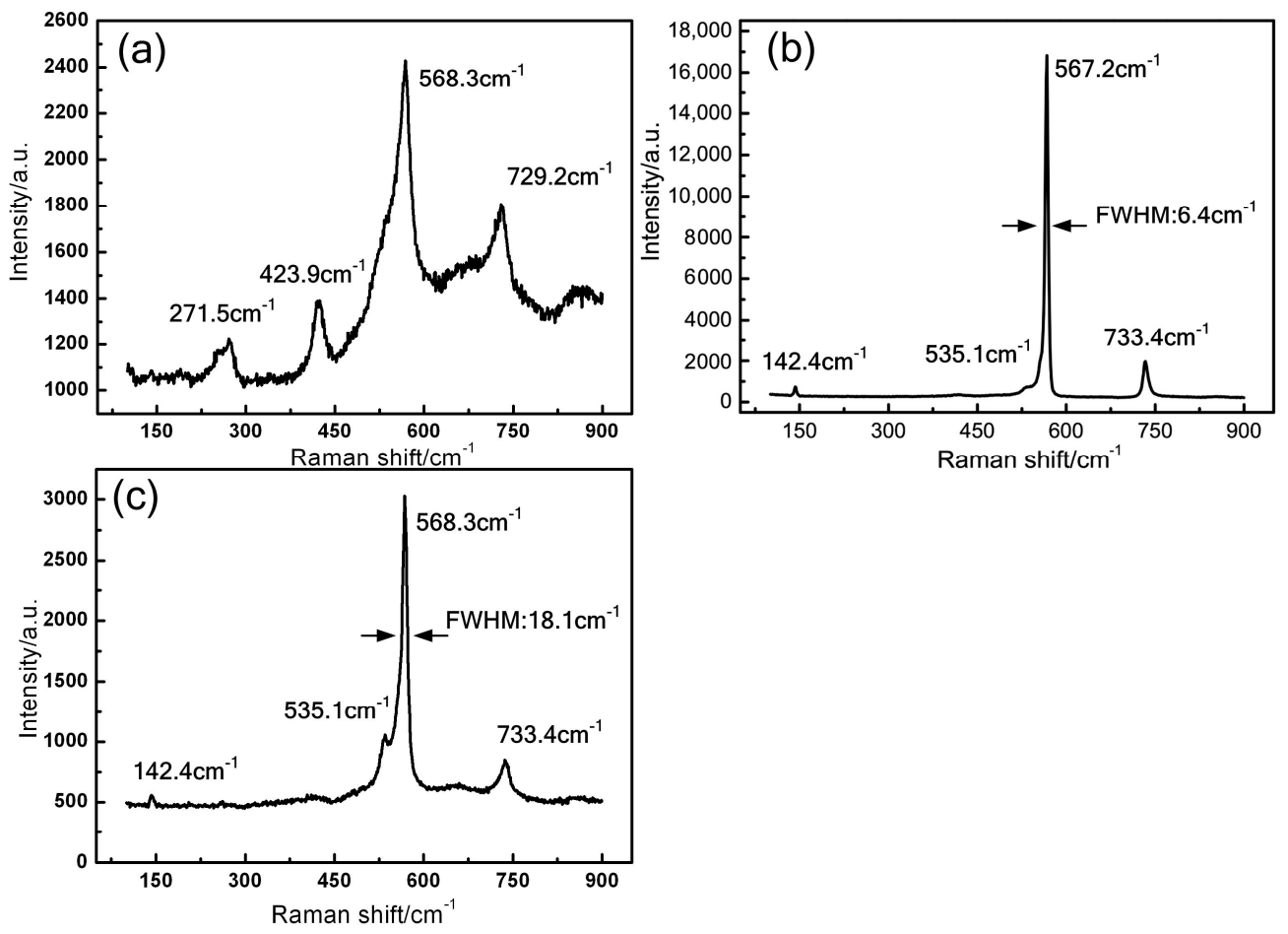

Figure 4. Raman spectra of GaN powder (a) and crystals obtained with $\mathrm{N}_{2}$ pressure of (b) $3.6 \mathrm{MPa}$ and (c) $4.5 \mathrm{MPa}$.

Table 1 shows the features of GaN crystals grown under different pressure. The mass of $\mathrm{GaN}$ decreases with the nitrogen pressure reduces, and no $\mathrm{GaN}$ powders are found in the solution at $0.4 \mathrm{MPa}$ nitrogen pressure. Because GaN has very high thermal stability below $900{ }^{\circ} \mathrm{C}$ [25], the loss $\mathrm{GaN}$ powders are considered to be completely dissolved into the solution. Therefore, the solubility of the solution can be inferred from loss mass of GaN powders. The results indicate that the solubility of $\mathrm{GaN}$ will increase with the decrease of nitrogen pressure. There are two equilibrium processes in the growth of $\mathrm{GaN}$ crystals by traditional flux method. One is $\mathrm{GaN}$ crystals growth due to supersaturation, and the other is nitrogen dissolves into the solution to form $\mathrm{N}$ ions. Both of these processes affect the concentration of $\mathrm{N}$ ion in the solution. Among them, the nitrogen dissolved into the metal solution followed the Sieverts' law [20]. It satisfies the following formula:

$$
X_{N}=k\left(P_{N_{2}}\right)^{1 / 2}
$$

$X_{N}$ is the solubility of nitrogen; $P_{N_{2}}$ is the nitrogen pressure; and $k$ is Sieverts' constant. According to the law, the concentration of $\mathrm{N}$ ions in solution is related to the pressure of nitrogen. When the nitrogen pressure decreases, the concentration of $N$ ions in the solution will decrease, which leads to dissolve more $\mathrm{GaN}$ in the solution. As a result, the solubility of $\mathrm{GaN}$ is improved. So, in the process of $\mathrm{GaN}$ crystal growth by recrystallization technology, it is necessary to control the nitrogen pressure to stabilize the concentration of $\mathrm{N}$ ions in the solution.

Table 1. Features of GaN crystals grown under different pressure.

\begin{tabular}{cccc}
\hline Pressure & Total Mass/g & Size $/ \mu \mathrm{m}$ & Morphology \\
\hline $0.4 \mathrm{MPa}$ & 0 & - & - \\
$3.6 \mathrm{MPa}$ & 2.33 & $10-100$ & Prism \\
$4.5 \mathrm{MPa}$ & 2.50 & $5-30$ & Prism, Pyramid \\
\hline
\end{tabular}

Kawamura et al. report that the yield of GaN can reach almost 100\% in Ga-Na melt [26]. It indicates that the GaN can be grown in the Na alloy melt with Ga ion. Therefore, a stable 
source of Ga ions is the key factor in the growth of GaN crystals. In our experiment, the Ga source comes from GaN powders at the bottom of the solution. So, the GaN powders will dissolved into the flux solution first. After the growth, GaN crystals with larger size were obtained at the gas-liquid interface at the upper part of the solution. It indicates that the Ga ion will transfer from bottom to the upper part of the solution due to the diffusion and convection. In addition, because the solution was in a negative temperature gradient condition and the Ga source came from $\mathrm{GaN}$ powders, it is inferred that the concentration of $\mathrm{Ga}$ at the bottom will be larger than that at the upper part. On the other hand, Nitrogen under high pressure will increase the concentration of $\mathrm{N}$ ions to form a supersaturated solution at the upper part of the solution, and the GaN crystal are grown. During this process, Ga ions in solution will be consumed, which make GaN powders at bottom dissolve into the solution. Finally, GaN crystals can be continuously grown at upper part of the solution. The problems of continuity and stability of $\mathrm{Na}$ flux method can be solved by this recrystallization technique and it is expected to obtain high quality GaN single crystals.

\section{Conclusions}

GaN crystals were obtained by recrystallization technique in $\mathrm{Na}$ alloy melt under $\mathrm{N}_{2}$ pressure of 3.6 $\mathrm{MPa}$ and $4.5 \mathrm{MPa}$. XRD results indicate that the samples are GaN with wurtzite type. The amount of remaining $\mathrm{GaN}$ crystals decrease with the nitrogen pressure reduce. The morphology of the crystal is mainly prism and pyramid. The size of the crystal increases when the position is close to the liquid surface. Raman experiments indicate that there is no stress in the GaN crystals, and GaN crystals grown at 3.6 MPa have high structural quality or low impurity concentrations. Moreover, the results revealed that the solubility and supersaturation of the solution are controlled by $\mathrm{N}_{2}$ pressure. There are two processes in crystal growth by recrystallization technique. First, the source of Ga provides from dissolution of $\mathrm{GaN}$ powders, which reaches the upper part of the solution due to diffusion and convection. Second, GaN crystals are obtained in the upper part of supersaturation solution due to high concentration of $\mathrm{N}$ ions under nitrogen pressure.

Author Contributions: Conceptualization, X.W.; methodology, X.W.; investigation, X.W.; resources, W.L., Y.L. and F.Z.; data curation, C.J.; supervision, H.W., Y.L. and Z.L.; funding acquisition, D.L. All authors have read and agreed to the published version of the manuscript.

Funding: This research received no external funding.

Institutional Review Board Statement: Not applicable.

Informed Consent Statement: Not applicable.

Data Availability Statement: Not applicable.

Acknowledgments: This work was financially supported by the Guangdong Basic and Applied Basic Research Foundation under Grant 2019A1515111068, the fund of Guangxi Key Laboratory of Wireless Wideband Communication and Signal Processing under Grant GXKL06190203, the Dongguan Social Science and Technology Development Project under Grant 2019507140172, the National Natural Science Foundation of China under Grants 11874111, 51771189, 61804028 and 61771138, the National Key Research and Development Program of China under Grant 2019YFC1511001, the Guangdong Educational Commission Program under Grant 2019KZDXM016, the Program of the Science and Technology Innovation Institute of Dongguan University of Technology under Grant KCYCXPT2017004, and the Dongguan Core Technology Frontier Project under Grant 2019622102012 and 2019622140003 .

Conflicts of Interest: The authors declare no conflict of interest. 


\section{References}

1. Zhang, Y.; Palacios, T. (Ultra)Wide-Bandgap Vertical Power FinFETs. IEEE Trans. Electron. Devices 2020, 67, 3960-3971. [CrossRef]

2. Kachi, T. Current status of GaN power devices. IEICE Electron. Express 2013, 10, 1-12. [CrossRef]

3. Nakamura, S.; Mukai, T.; Senoh, M. Candela-class high-brightness InGaN/AlGaN double-heterostructure blue-light-emitting diodes. Appl. Phys. Lett. 1994, 64, 1687-1689. [CrossRef]

4. Avrutin, V.; Silversmith, D.J.; Mori, Y.; Kawamura, F.; Kitaoka, Y.; Morkoc, H. Growth of Bulk GaN and AlN: Progress and Challenges. Proc. IEEE 2010, 98, 1302-1315. [CrossRef]

5. Amano, H. Progress and Prospect of the Growth of Wide-Band-Gap Group III Nitrides: Development of the Growth Method for Single-Crystal Bulk GaN. Jpn. J. Appl. Phys. 2013, 52, 050001. [CrossRef]

6. Kucharski, R.; Sochacki, T.; Lucznik, B.; Bockowski, M. Growth of bulk GaN crystals. J. Appl. Phys. 2020, 128, 050902. [CrossRef]

7. Yamane, H.; Kinno, D.; Shimada, M.; Sekiguchi, T.; Disalvo, F.J. GaN single crystal growth from a Na-Ga melt. J. Mater. Sci. 2000, 35, 801-808. [CrossRef]

8. Yamane, H.; Shimada, M.; Clarke, S.J.; DiSalvo, F.J. Preparation of GaN Single Crystals Using a Na Flux. Chem. Mat. 1997, 9, 413-416. [CrossRef]

9. von Dollen, P.; Pimputkar, S.; Alreesh, M.A.; Nakamura, S.; Speck, J.S. A new system for sodium flux growth of bulk GaN. Part II: In situ investigation of growth processes. J. Cryst. Growth 2016, 456, 67-72. [CrossRef]

10. von Dollen, P.; Pimputkar, S.; Alreesh, M.A.; Albrithen, H.; Suihkonen, S.; Nakamura, S.; Speck, J.S. A new system for sodium flux growth of bulk GaN. Part I: System development. J. Cryst. Growth 2016, 456, 58-66. [CrossRef]

11. Imade, M.; Murakami, K.; Matsuo, D.; Imabayashi, H.; Takazawa, H.; Todoroki, Y.; Kitamoto, A.; Maruyama, M.; Yoshimura, M.; Mori, Y. Centimeter-Sized Bulk GaN Single Crystals Grown by the Na-Flux Method with a Necking Technique. Cryst. Growth Des. 2012, 12, 3799-3805. [CrossRef]

12. Kawamura, F.; Tanpo, M.; Miyoshi, N.; Imade, M.; Yoshimura, M.; Mori, Y.; Kitaoka, Y.; Sasaki, T. Growth of GaN single crystals with extremely low dislocation density by two-step dislocation reduction. J. Cryst. Growth 2009, 311, 3019-3024. [CrossRef]

13. Wu, X.; Hao, H.; Li, Z.; Fan, S.; Xu, Z. GaN crystals growth in the Na-Li-Ca flux by liquid phase epitaxy (LPE) technique. J. Cryst. Growth 2019, 521, 30-33. [CrossRef]

14. Mori, Y.; Imanishi, M.; Murakami, K.; Yoshimura, M. Recent progress of Na-flux method for GaN crystal growth. Jpn. J. Appl. Phys. 2019, 58, SC0803. [CrossRef]

15. Imade, M.; Maruyama, M.; Yoshimura, M.; Mori, Y. Growth of bulk GaN crystals by the Na-flux point seed technique. Jpn. J. Appl. Phys. 2014, 53, 05FA06. [CrossRef]

16. Imade, M.; Imanishi, M.; Todoroki, Y.; Imabayashi, H.; Matsuo, D.; Murakami, K.; Takazawa, H.; Kitamoto, A.; Maruyama, M.; Yoshimura, M.; et al. Fabrication of low-curvature 2 in. GaN wafers by Na-flux coalescence growth technique. Appl. Phys. Express 2014, 7. [CrossRef]

17. Jones, E.A.; Wang, F.; Costinett, D. Review of Commercial GaN Power Devices and GaN-Based Converter Design Challenges. IEEE J. Emerg. Sel. Top. Power Electron. 2016, 4, 707-719. [CrossRef]

18. Aoki, M.; Yamane, H.; Shimada, M.; Sarayama, S.; Iwata, H.; Disalvo, F. Dissolution and Recrystallization of GaN in Molten Na. Jpn. J. Appl. Phys. 2003, 42, 7272-7275. [CrossRef]

19. Aoki, M.; Yamane, H.; Shimada, M.; Sarayama, S.; Iwata, H.; DiSalvo, F.J. Single crystal growth of GaN by the temperature gradient Na flux method. J. Cryst. Growth 2004, 266, 461-466. [CrossRef]

20. Kawamura, F.; Morishita, M.; Omae, K.; Yoshimura, M.; Mori, Y.; Sasaki, T. The effects of Na and some additives on nitrogen dissolution in the Ga-Na system: A growth mechanism of GaN in the Na flux method. J. Mater. Sci. Mater. Electron. 2005, 16, 29-34. [CrossRef]

21. Morishita, M.; Kawamura, F.; Kawahara, M.; Yoshimura, M.; Mori, Y.; Sasaki, T. Promoted nitrogen dissolution due to the addition of Li or Ca to Ga-Na melt; some effects of additives on the growth of GaN single crystals using the sodium flux method. J. Cryst. Growth 2005, 284, 91-99. [CrossRef]

22. Wu, X.; Hao, H.; Li, Z.; Fan, S.; Xu, Z. Fabrication of GaN single crystals at $700{ }^{\circ} \mathrm{C}$ using Na-Li-Ca mixed flux system. AIP Adv. 2018, 8, 055326. [CrossRef]

23. Goñi, A.R.; Siegle, H.; Syassen, K.; Thomsen, C.; Wagner, J.M. Effect of pressure on optical phonon modes and transverse effective charges in GaN and AlN. Phys. Rev. B 2001, 64, 035205. [CrossRef]

24. Perlin, P.; Jauberthiecarillon, C.; Itie, J.P.; Miguel, A.S.; Grzegory, I.; Polian, A. Raman scattering and x-ray-absorption spectroscopy in gallium nitride under high pressure. Phys. Rev. B 1992, 45, 83-89. [CrossRef] [PubMed]

25. Song, Y.T.; Wu, X.; Wang, W.J.; Yuan, W.X.; Chen, X.L. Thermal stability and electronic specific heat of GaN. J. Alloy. Compd. 2004, 370, 65-68. [CrossRef]

26. Kawamura, F.; Morishita, M.; Tanpo, M.; Imade, M.; Yoshimura, M.; Kitaoka, Y.; Mori, Y.; Sasaki, T. Effect of carbon additive on increases in the growth rate of 2 in GaN single crystals in the Na flux method. J. Cryst. Growth 2008, 310, 3946-3949. [CrossRef] 